\title{
Biologia reprodutiva de Copaifera langsdorffii Desf. (Leguminosae, Caesalpinioideae)
}

\author{
CRISTIANE V. FREITAS ${ }^{1}$ e PAULO E. OLIVEIRA ${ }^{2,3}$
}

(recebido: 24 de outubro de 2001; aceito: 22 de maio de 2002)

\begin{abstract}
Reproductive biology of Copaifera langsdorffii Desf. (Leguminosae, Caesalpinioideae). A survey on the phenology and reproductive biology of Copaifera langsdorffii Desf. was carried out in a cerradão area at Fazenda Capim Branco, Uberlândia, MG. Flowering occurs during the rain season and seed dispersal during the dry season. Flowers are palegreen, $0.5 \mathrm{~cm}$ in diameter, weakly zigomorphic and organized in paniculate inflorescences. They are highly odoriferous, oneday flowers. Anthesis begins at about 5:00 h. The nectar production is very small $(0.2 \mu \mathrm{l})$ with $49 \%$ of sucrose equivalents. The most frequent flower visitors and pollinators were Apis mellifera, Scaptotrigona cf. depiles and Trigona spinipes bees. Controlled hand-pollinations showed that the species is mostly self-sterile and non-apomictic. However, pollen tubes were observed growing down to the ovary and penetrating the ovules in self-pollinated pistils, a fact which suggests late-acting selfsterility phenomena or inbreeding depression. Fruit-set was always low and related to low flower to fruit conversion, may be due to inefficient pollination and fruit predation.
\end{abstract}

RESUMO - (Biologia reprodutiva de Copaifera langsdorffii Desf. (Leguminosae, Caesalpinioideae). Copaifera langsdorffii Desf. é uma espécie da família Leguminosae, subfamília Caesalpinioideae, de ampla distribuição no Brasil. O estudo da biologia reprodutiva desta espécie foi realizado numa área de cerradão aberto para pastagem da Fazenda Capim Branco, Uberlândia, MG. A espécie floresce durante o período das chuvas e dispersa suas sementes na época seca. As flores são branco-esverdeadas, com cerca de $0,5 \mathrm{~cm}$ de diâmetro, fracamente zigomorfas e estão reunidas em inflorescência paniculada. Apresentam um forte odor adocicado e duram apenas um dia. A antese inicia-se por volta das 5:00 h. Os recursos oferecidos aos visitantes são pólen e néctar. Produzem pouco néctar $(0,2 \mu \mathrm{l})$ com concentração média de $49 \%$ de equivalentes de sacarose. Os visitantes mais freqüentes foram as abelhas Apis mellifera, Scaptotrigona cf. depiles e Trigona spinipes. Os resultados das polinizações manuais e o índice de incompatibilidade (ISI) indicam que a espécie é auto-incompatível e não apomítica. No entanto, foram observados tubos polínicos crescendo até o ovário e penetrando os óvulos em flores autopolinizadas, sugerindo a ocorrência de fenômenos de auto-esterilidade de ação tardia ou depressão endogâmica. A baixa produção de frutos está relacionada à pequena conversão de flores em frutos e também à predação dos frutos.

Key words - Cerrado, savanna, bee pollination, self-sterility, inbreeding depression

\section{Introdução}

Na medida em que a importância da reprodução sexuada de plantas do bioma Cerrado fica evidente (Oliveira \& Silva 1993, Saraiva et al. 1996, Gibbs \& Sassaki 1998; Oliveira \& Gibbs 2000), pesquisas acerca dos mecanismos envolvidos em todas as suas etapas tornam-se cada vez mais necessárias. Para as espécies lenhosas do Cerrado, foram encontrados padrões semelhantes aos das plantas de comunidades florestais, apresentando uma grande diversidade de sistemas de polinização e predominância de plantas xenógamas obrigatórias (Oliveira \& Gibbs 2000). As áreas do Cerrado como um todo, inclusive as matas da região,

\footnotetext{
1. Universidade de Brasília, Departamento de Ecologia, Caixa Postal 04457, 70919-970 Brasília, DF, Brasil.

2. Universidade Federal de Uberlândia, Instituto de Biociências, Caixa Postal 593, 38400-902 Uberlândia, MG, Brasil.

3._Autor para correspondência: poliveira@ufu.br
}

têm sofrido profundas transformações de natureza antrópica, apresentando crescente processo de degradação (Ratter et al. 1997). Sendo assim, o desenvolvimento de pesquisas básicas sobre os processos ecológicos envolvidos na reprodução das plantas do Cerrado é fundamental para uma melhor compreensão da diversidade estrutural e funcional deste bioma e consequentemente para o desenvolvimento de ferramentas úteis para a conservação e manejo destes sistemas.

Existem algumas espécies de plantas que são particularmente importantes nestes ambientes, pois aparecem tanto em áreas de cerrado aberto como em áreas de floresta. Copaifera langsdorffii Desf. é uma dessas espécies, ocorrendo em mata de galeria, mata mesofítica de interflúvio, cerradão distrófico e cerrado (Almeida et al. 1998).

Copaifera langsdorffii é uma árvore que atinge até $35 \mathrm{~m}$ de altura, distribui-se desde o nordeste da Argentina até a Venezuela, sendo encontrada em todo 
território brasileiro (Machado 1990). É uma espécie emergente do dossel das matas ciliares no Distrito Federal (Leite \& Salomão 1992) e no Triângulo Mineiro (Schiavini 1997, Resende et al. 1997). Aparece comumente em solos bem drenados e, de maneira geral, cresce melhor em solos de matas ciliares e matas semidecíduas, do que em solo de cerrado (Machado 1990).

A biologia de polinização de Copaifera langsdorffii foi estudada anteriormente por Crestana \& Kageyama (1989) na Estação Experimental de Mogi-Guaçu, SP. O estudo foi desenvolvido em termos da descrição da morfologia floral e observação do comportamento dos insetos visitantes, mas deixou uma série de lacunas, principalmente no que diz respeito ao sistema de reprodução e eficiência da polinização para a produção de frutos. Na medida em que já existem muitos estudos sobre dinâmica populacional e de frutificação (Leite \& Salomão 1992, Pedroni 1995), dados sobre sistemas de polinização e reprodução podem completar as informações e permitir uma visão global da dinâmica reprodutiva e história de vida da espécie.

\section{Material e métodos}

O presente estudo foi realizado numa área de cerradão aberto para pastagem na Fazenda Capim Branco, $8 \mathrm{~km}$ da sede do município de Uberlândia (18 $59^{\prime}$ S e $48^{\circ} 18^{\prime} \mathrm{W}$ ). Além da abertura para a pastagem, a área foi pouco modificada e é contígua a uma extensa área de vegetação natural do "Clube Caça e Pesca Itororó de Uberlândia".

O clima da região é do tipo Aw, segundo a classificação de Köppen, caracterizado por apresentar inverno frio e seco e verão quente e chuvoso (Rosa et al. 1991). Os dados de temperatura média mensal, umidade média mensal e precipitação total mensal foram obtidos da Estação Climatológica do Instituto de Geografia da Universidade Federal de Uberlândia, a cerca de $10 \mathrm{~km}$ da área estudada.

O estudo foi realizado de outubro de 1999 a novembro de 2000. O acompanhamento fenológico de 22 indivíduos de Copaifera langsdorfii Desf. foi realizado quinzenalmente durante todo este período, no entanto, na época de floração e início da frutificação foi realizado semanalmente. Os indivíduos escolhidos foram marcados com etiqueta metálica. Foram observadas cinco fenofases: brotação, botões, floração, frutificação e perda de folhas, que foram descritas por notas de intensidade. As notas atribuídas foram: 0 indicando ausência da fenofase; 1,2 e 3 presença da fenofase, respectivamente nos intervalos de $1 \%$ a $10 \%, 10 \%$ a $50 \%$ e acima de $50 \%$ dos ramos apresentando a fenofase descrita. Considerou-se como brotamento, o surgimento de folhas novas, pequenas, de cor laranja-avermelhada; e perda de folhas, a senescência foliar, onde as folhas ficam com uma cor verde escura, com tons castanhos. O período de floração foi indicado pela presença de botões e a frutificação pelo início da formação dos frutos e sua presença nas plantas até a dispersão das sementes. Consideraram-se como picos os períodos de maior intensidade de cada fenofase.

A morfologia floral foi estudada a partir de material fresco e fixado em álcool $70 \%$. Foram feitas fotos e desenhos das flores, observações sobre a posição da flor na planta, duração das flores, características de coloração e disposição do gineceu e androceu, utilizando métodos descritos de maneira geral em Kearns \& Inouye (1993).

As flores foram marcadas com linhas coloridas antes da abertura e observadas periodicamente para estabelecer o horário da antese. Foi anotado, ainda, o número de flores em 248 inflorescências e observada a quantidade de flores que abriram por dia.

A quantidade de néctar produzido pelas flores abertas foi verificada utilizando-se micropipetas para extração e medidas do volume de néctar. Refratômetro de mão foi utilizado para estimar a concentração em "equivalentes de sacarose" (Inouye et al. 1980). Foram feitas 10 medidas de concentração, sendo que para se obter uma quantidade mínima para cada medida foi necessário extrair o néctar de sete flores diferentes.

O material botânico testemunho encontra-se depositado no Herbário da Universidade Federal de Uberlândia (HUFU 22.510).

Durante o período de floração, foi observado o comportamento dos visitantes na flor e ao deixar a flor, verificando se carregavam pólen e em que região do corpo o pólen estava depositado. Os visitantes florais foram, sempre que possível, fotografados. Exemplares testemunha estão depositados na coleção entomológica do Instituto de Biologia,UFU.

Para o estudo do sistema reprodutivo, foram feitos testes de polinizações controladas (adaptados de Bawa (1974)) em 12 árvores adultas, no período de floração de dezembro de 1999 a fevereiro de 2000. Botões em pré-antese foram isolados em sacos de organza e as flores resultantes foram submetidas aos seguintes tratamentos: autopolinizações espontâneas, nas quais as flores foram previamente ensacadas e deixadas intactas para a verificação da formação ou não do fruto; autopolinizações manuais, nas quais as flores foram previamente ensacadas e efetuadas polinizações com pólen da própria flor ou de outras flores do mesmo indivíduo (geitonogamia); polinização cruzada, nas quais as flores foram previamente ensacadas e polinizadas com pólen de flores de indivíduos diferentes distantes pelo menos $15 \mathrm{~m}$. Para a avaliação da eficiência de polinização natural, flores foram marcadas e mantidas expostas, sendo verificado o número de frutos formados (controle).

Visando minimizar possíveis influências nos resultados das polinizações, os sacos de organza foram retirados dois dias após as polinizações manuais. Com isso, os frutos desenvolveram-se livremente.

Foi calculado o "Índice de auto-incompatibilidade" (ISI sensu Bullock 1985), sendo o mesmo encontrado pela divisão 
do percentual de frutificações provenientes de autopolinizações pelo percentual de frutificações oriundas de polinizações cruzadas. Foi, ainda, calculada a eficácia reprodutiva, que é a razão entre o percentual de frutos formados por polinização aberta (controle) e o dos frutos formados por polinização cruzada manual (Zapata \& Arroyo 1978).

Pistilos tratados com polinizações cruzadas e com autopolinizações manuais, bem como de flores mantidas em condições naturais, foram coletados e fixados em álcool 70\% em intervalos de 24, 48 e 72 horas após a antese. Estes foram levados para o laboratório onde, utilizando-se a técnica de microscopia de fluorescência (Martin 1959), observou-se o crescimento dos tubos polínicos. Para avaliar se os diferentes tratamentos implicavam em diferenças na deposição de pólen no estigma e no crescimento de tubos polínicos nos pistilos observados, foi utilizado o teste G (Sokal \& Rohlf 1981).

Para determinar a produção de frutos, foram feitos censos quinzenais das flores que foram submetidas a polinizações manuais e naturais (controle), observando o desenvolvimento dos frutos até a dispersão das sementes, de acordo com Nic-Lughadha (1998). Foi feito, ainda, um acompanhamento quinzenal de outros 297 frutos, já desenvolvidos, marcados em cinco indivíduos, de 19/05/2000 até 09/10/2000. A partir deste acompanhamento, estimou-se o percentual de frutos desenvolvidos que caem antes da maturação e verificou-se se eram predados ou danificados fisicamente, com conseqüente exposição e/ou perda da(s) semente(s).

\section{Resultados}

Fenologia - Copaifera langsdorffii apresentou comportamento fenológico sazonal (figura 1). A fenofase de perda de folhas foi praticamente constante durante todo o ano, com os indivíduos com folhas senescentes a cada mês em pequena quantidade. A produção de folhas novas também foi uma atividade constante e de baixa intensidade durante o período de observação. Os indivíduos observados mantiveram aspecto sempre-verde durante todo o ano (figura 2).

A emissão de botões florais em 1999 se iniciou no final de outubro e se estendeu até o início de abril de 2000, sendo o seu máximo em janeiro. O início da emissão de botões da mesma forma e intensidade ocorreu também em outubro de 2000. Dos 22 indivíduos observados, apenas dois não floresceram. Esta fenofase ocorreu gradualmente durante um período de cinco meses. A mais intensa floração ocorreu em janeiro e fevereiro, correspondendo ao período mais quente e úmido do ano. Pode-se observar na figura 1 , a ocorrência de episódios mais ou menos sincrônicos de presença de flores abertas, seguidos de períodos onde foram observados apenas botões.
Frutos imaturos começaram a ser observados em dezembro. O desenvolvimento dos frutos continuou até julho do ano seguinte. Frutos maduros foram observados de junho até setembro, coincidindo com a época de maior perda das folhas. A intensidade máxima de frutificação ocorreu no mês de março, seguida de perdas devidas a aborto e predação. A dispersão das sementes iniciou-se em junho e estendeu-se até setembro.

Biologia e visitantes florais - As flores de Copaifera langsdorffii estão reunidas em inflorescências paniculadas, terminais, multifloras, com uma média de 125 flores $( \pm 46,50 ; \mathrm{n}=248)$. As flores são hermafroditas, branco-esverdeadas, opacas e têm cerca de $0,5 \mathrm{~cm}$ de diâmetro. As pétalas estão ausentes e o cálice é formado por quatro sépalas livres, sendo uma mais larga, que caracteriza simetria fracamente zigomorfa (figura 3). As flores produzem odor intenso, suave e doce, desde a abertura.

$\mathrm{O}$ androceu é composto por 10 estames, de dois tamanhos diferentes, que se apresentam implantados intercaladamente, maiores e menores, em cada lado de um disco nectarífero de cor verde-escura, na base do ovário. As anteras têm deiscência lateral e longitudinal e são dorsifixas. O ovário é súpero, unilocular, com dois a três óvulos de placentação sutural e o estilete é inclinado, formando um ângulo no quarto superior. $\mathrm{O}$ estigma é pequeno, papiloso e seco.

As flores têm antese matutina, abrindo nas primeiras horas da manhã, por volta das 5:00 h. As primeiras flores a se abrirem são as da base dos racemos que constituem cada panícula, havendo grande variação na quantidade que se abre por dia. O estigma parece estar receptivo a partir das 8:00 h, quando os grãos de pólen também passam a estar disponíveis, mas foi impossível definir com exatidão o período de receptividade.

Os recursos oferecidos pelas flores aos visitantes são pólen e néctar. A média da concentração de açucares (equivalentes de sacarose) no néctar de Copaifera langsdorffii foi de $49 \%( \pm 2 ; \mathrm{n}=10)$. O volume médio de néctar por flor foi de $0,2 \mu 1( \pm 0,1 ; \mathrm{n}=10)$.

As flores a partir do segundo dia já mostram sinais de senescência, não produzindo néctar nem odor. As sépalas vão se tornando amareladas e as anteras ficam vazias e retorcidas. Os pistilos não polinizados secam lentamente e caem ao longo de três dias. Já nos pistilos polinizados, o desenvolvimento dos frutos é relativamente lento; o ovário começa a se dilatar e demora cerca de dois meses para se desenvolver completamente. 

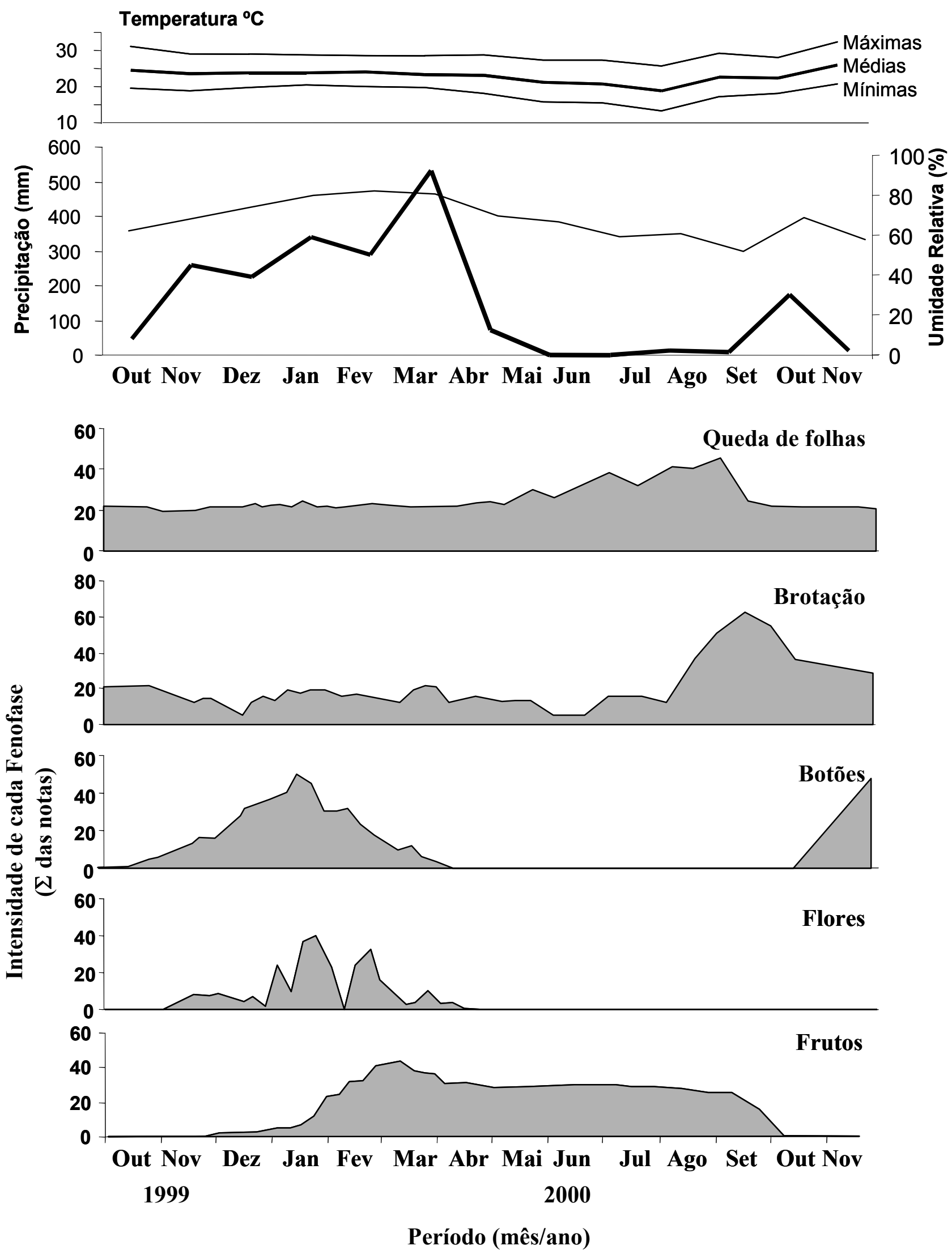

Figura 1. Climatograma do período de estudo e caracterização da fenologia reprodutiva e vegetativa de Copaifera langsdorffii no período de outubro de 1999 a novembro de 2000. 

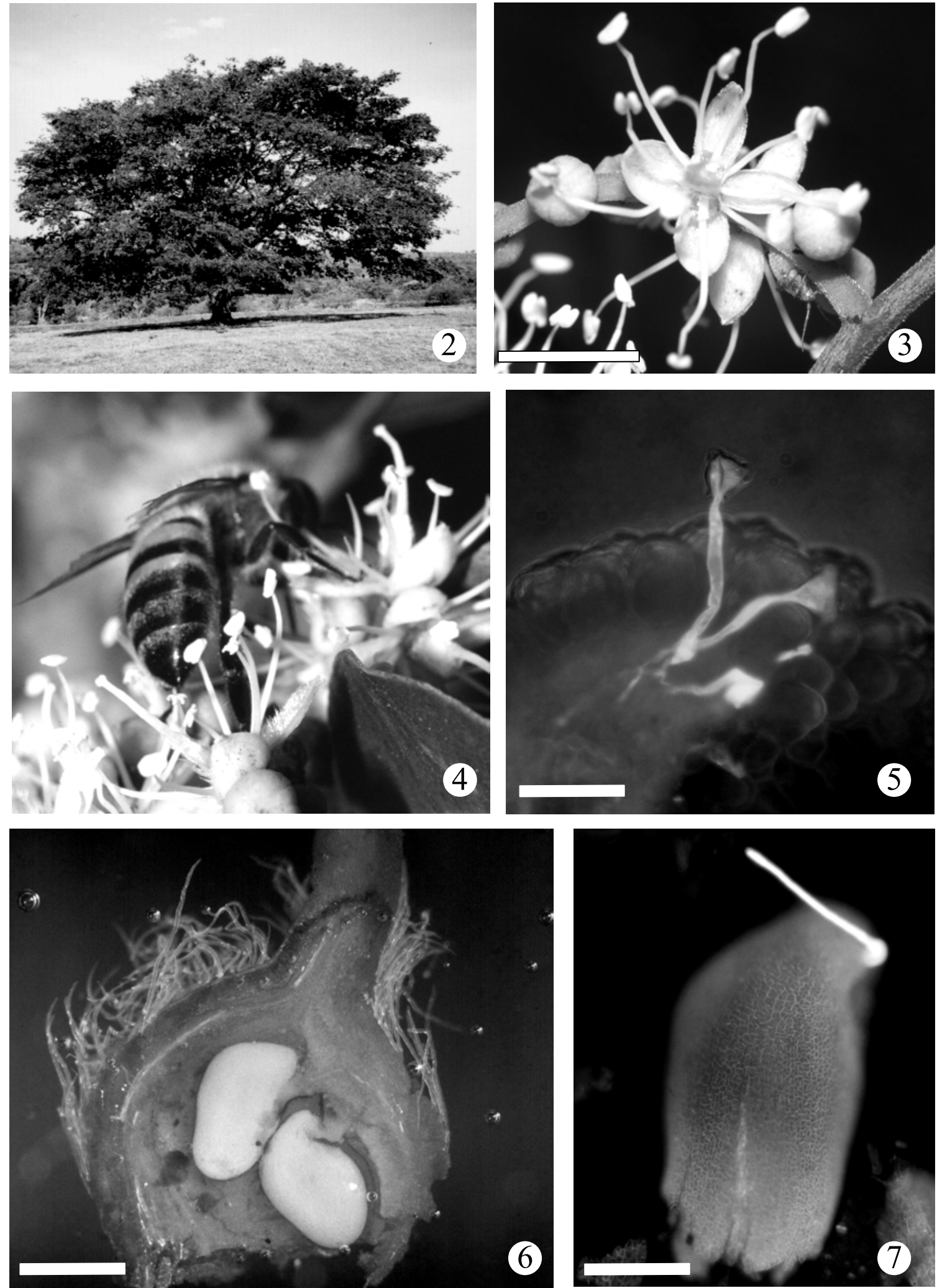

Figuras 2-7. Diferentes aspectos da biologia reprodutiva de Copaifera langsdorffii. 2. Indivíduo adulto, com as folhas verdes, na área de estudo (aprox. $15 \mathrm{~m}$ altura). 3. Flor aberta com sépala mais larga diferenciada (escala $=4 \mathrm{~mm}$ ). 4. Apis mellifera visitando inflorescência. 5. Parte do estigma de Copaifera langsdorffii, mostrando grãos de pólen germinando e as papilas estigmáticas (escala $=20 \mu \mathrm{m})$. 6. Corte transversal do pistilo mostrando a posição dos óvulos (escala $=80 \mu \mathrm{m})$. 7. Penetração do tubo polínico no óvulo (escala $=20 \mu \mathrm{m})$. 
Ao longo da floração, as flores de Copaifera langsdorffii foram intensamente visitadas por diversos insetos, principalmente Apidae e Vespidae (tabela 1). Foram observadas sete espécies de abelhas, pertencentes a quatro famílias, além de outros insetos.

Tabela 1. Visitantes florais observados durante os meses de dez/1999 a mar/2000, em flores de Copaifera langsdorffii numa área de cerradão da Fazenda Capim Branco, Uberlândia, MG.

\begin{tabular}{|c|c|}
\hline Ordem / Família & Espécies \\
\hline $\begin{array}{l}\text { HYMENOPTERA } \\
\text { Apidae } \\
\text { Apinae - Apini }\end{array}$ & Apis mellifera (Linnaeus 1758) \\
\hline Apinae - Meliponini & $\begin{array}{l}\text { Scaptotrigona cf. depiles (Moure 1942) } \\
\text { Trigona spinipes (Fabricius 1793) }\end{array}$ \\
\hline Apinae - Exomalopsini & Exomalopsis sp. \\
\hline Halictidae & $\begin{array}{l}\text { Augochlorella sp. } \\
\text { Temnosoma } \mathrm{sp} .\end{array}$ \\
\hline Vespidae & Espécies não identificadas \\
\hline Formicidae & Espécies não identificadas \\
\hline LEPIDOPTERA & Espécies não identificadas \\
\hline DIPTERA & Ornidia obesa (Fabricius 1775) \\
\hline
\end{tabular}

Quanto ao comportamento dos insetos na flor, podese dizer que as visitas em geral iniciavam-se por volta das 6:00 h, intensificando-se ao longo da manhã, sendo o período de maior atividade entre 10:00 h e 13:00 h. A partir desse horário, as visitas começaram a diminuir, porém até o entardecer ainda se observaram visitantes nas flores.

Entre as abelhas, o comportamento foi semelhante. Todas as abelhas são pequenas e ao chegarem próximo à flor, pousam nas sépalas, caminham sobre os estames e coletam pólen e néctar ativamente. No processo, elas ficam com todo o corpo sujo de pólen e em seguida voam em direção a outras flores, onde contatam novamente com estigmas. Apis mellifera foi o visitante mais freqüente (figura 4), seguida da Scaptotrigona $\mathrm{cf}$. depiles e Trigona spinipes. Todas elas carregam muito pólen e são os polinizadores efetivos.

Os outros insetos observados (borboletas, vespas, formigas, besouros e moscas) tiveram uma menor freqüência, aparecendo esporadicamente. Não foram considerados como polinizadores, mesmo porque muitas vezes não tocaram no estigma ou anteras, coletando apenas néctar.

Sistema reprodutivo e frutificação - C. langsdorffii forma frutos preferencialmente através de polinizações cruzadas (tabela 2). Não houve formação de frutos por autopolinização espontânea, o que indica que a espécie não se reproduz sem o trabalho dos polinizadores e, ainda, afasta a possibilidade de apomixia. O sucesso de frutificação das flores oriundas de autopolinização manual foi muito baixo $(0,14 \%)$. Obteve-se o índice de auto-incompatibilidade (ISI) de 0,09, indicando ser esta uma espécie fortemente auto-estéril.

A taxa de formação de frutos em condições naturais (controle) foi de $0,5 \%$, sendo menor que a taxa de polinização cruzada manual $(1,5 \%)$ e a eficácia reprodutiva de 0,35 (sensu Zapata \& Arroyo 1978).

A análise dos pistilos em microscopia de fluorescência (figuras 5-7) permitiu observar tubos polínicos germinando e crescendo no estilete de flores com polinização aberta, autopolinização manual e polinização cruzada (figura 5). Tubos polínicos de polinização cruzada e autopolinização manual apresentam comportamento semelhante. Após 24 horas foram observados tubos polínicos crescendo até o ovário em todos os tratamentos. No ovário foi observada penetração no óvulo a partir de 24 horas em flores oriundas de polinização cruzada, autopolinização manual e controles (figura 6).

Tabela 2. Resultados das polinizações controladas das flores de Copaifera langsdorffii, com os valores de sucesso reprodutivo em cada tratamento, realizadas numa área de cerradão da Fazenda Capim Branco, Uberlândia, MG.

\begin{tabular}{lcccc}
\hline Polinizações controladas & $\begin{array}{c}\text { n. de } \\
\text { tratamentos }\end{array}$ & $\begin{array}{c}\text { Frutos } \\
\text { iniciados }\end{array}$ & $\begin{array}{c}\text { Frutos } \\
\text { desenvolvidos }\end{array}$ & $\begin{array}{c}\text { Frutos } \\
\text { maduros }\end{array}$ \\
\hline Controle (Polinização aberta) & 33.346 & $1.323(4 \%)$ & $176(0,5 \%)$ & $97(0,3 \%)$ \\
Polinização cruzada & 2.376 & $504(21 \%)$ & $35(1,5 \%)$ & $24(1 \%)$ \\
Autopolinização manual & 2.119 & $530(25 \%)$ & $3(0,14 \%)$ & $1(0,04 \%)$ \\
Autopolinização espontânea & 2.723 & 0 & 0 & 0,1 \\
& & & & 0 \\
\hline
\end{tabular}


Para 72 horas, parece haver um número significativamente maior de pistilos de polinização cruzada com tubos polínicos crescendo no estilete e no ovário, sugerindo que a eficiência no crescimento dos tubos polínicos pode ser diferente entre os tratamentos (tabela 3).

O sucesso de desenvolvimento de frutos desde a polinização até o início da maturação também variou entre tratamentos (figura 8). Nota-se que, para todos os tipos de frutos formados houve uma queda brusca nos primeiros meses de desenvolvimento. Após esta grande perda inicial, os frutos formados por polinização cruzada mantiveram-se em maior número até a maturação. Os poucos frutos oriundos de autopolinizações manuais que permaneceram nas árvores apresentaram desenvolvimento aparentemente normal.

Momentos críticos do desenvolvimento dos frutos foram comparados (tabela 2). Foi denominada "Frutos iniciados", a fase referente ao primeiro censo, que foi realizado no dia 26/02/2000; a fase "Frutos desenvolvidos" correspondeu ao censo realizado no dia 15/07/2000, que antecedeu o início da abertura dos frutos e "Frutos maduros" correspondeu aos frutos remanescentes que se abriram efetivamente e dispersaram as sementes.

Das 33.346 flores marcadas para controle, somente $176(0,5 \%)$ formaram frutos desenvolvidos. Destes frutos, 97 (55\% dos frutos desenvolvidos) chegaram à fase de maturação. Para o total das polinizações cruzadas houve desenvolvimento de 35 frutos $(1,5 \%)$,

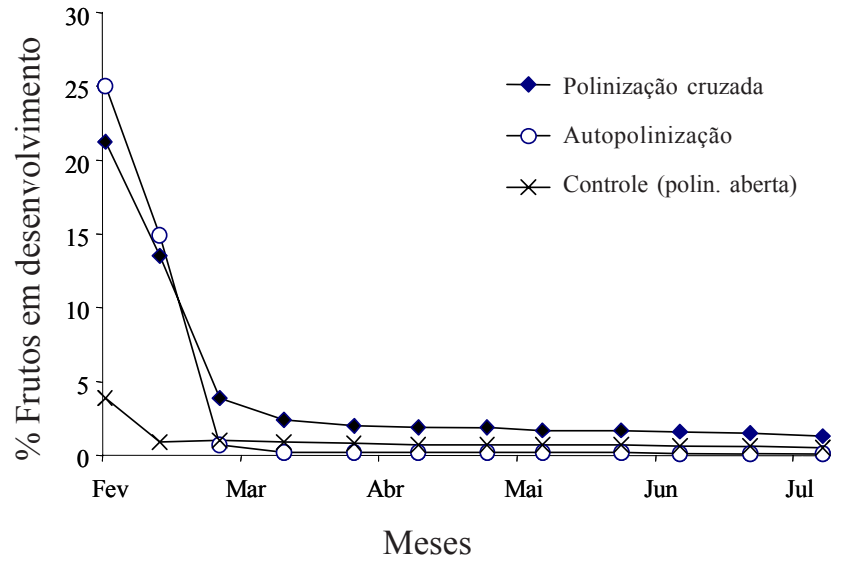

Figura 8. Porcentagem de frutos em desenvolvimento a partir das polinizações controladas em Copaifera langsdorffii no período de fevereiro a julho de 2000.

sendo que 24 (69\% dos frutos desenvolvidos) abriram e dispersaram as sementes. Nas autopolinizações manuais apenas três frutos $(0,14 \%)$ chegaram à fase final de desenvolvimento e apenas um fruto à fase de maturação (33\% dos frutos desenvolvidos).

A partir do acompanhamento quinzenal de 297 frutos desenvolvidos, marcados ao acaso após o dia 15/07/2000, verificou-se que há uma grande perda antes da maturação e esta perda está relacionada com a alta taxa de predação (56\%). Duas espécies de insetos predadores de sementes foram encontradas desenvolvendo-se nas sementes, Rhinochenus brevicollis Chevr. e Spermalogus cf. copaiferae Marshall. (Coleoptera: Curculionidae), encontrados em

Tabela 3. Resultados da análise do crescimento dos tubos polínicos das flores submetidas à polinização cruzada, autopolinização manual e controle, após 24, 48 e 72 h da população de Copaifera langsdorffii da Fazenda Capim Branco, Uberlândia, MG. Letras iguais significam que não há diferença significativa estatisticamente entre os valores e letras diferentes significam que os valores são diferentes estatisticamente $(\mathrm{p}<0,05)$.

\begin{tabular}{lccc}
\hline Tratamentos & $\begin{array}{c}\text { N. de pistilos } \\
\text { observados }\end{array}$ & $\begin{array}{c}\text { Pistilos com } \\
\text { grãos de pólen }\end{array}$ & $\begin{array}{c}\text { Pistilos com } \\
\text { tubo polínico }\end{array}$ \\
\cline { 2 - 4 } & & Estigma & Estilete/ovário \\
\hline Polinização cruzada $-24 \mathrm{~h}$ & 14 & $11 \mathrm{a}$ & $6 \mathrm{a}$ \\
Autopolinização $-24 \mathrm{~h}$ & 15 & $8 \mathrm{a}$ & $8 \mathrm{a}$ \\
Controle - $24 \mathrm{~h}$ & 17 & $16 \mathrm{a}$ & $10 \mathrm{~b}$ \\
Polinização cruzada $-48 \mathrm{~h}$ & 8 & $6 \mathrm{a}$ & $3 \mathrm{a}$ \\
Autopolinização $-48 \mathrm{~h}$ & 11 & $3 \mathrm{~b}$ & $3 \mathrm{a}$ \\
Controle - 48 h & 11 & $10 \mathrm{a}$ & $9 \mathrm{~b}$ \\
Polinização cruzada $-72 \mathrm{~h}$ & 12 & $1 \mathrm{a}$ & $7 \mathrm{a}$ \\
Autopolinização $-72 \mathrm{~h}$ & 15 & $2 \mathrm{a}$ & $3 \mathrm{~b}$ \\
Controle - 72 h & 20 & $14 \mathrm{~b}$ & $11 \mathrm{a}$ \\
\hline
\end{tabular}


outras populações de Copaifera langsdorffii no Estado de São Paulo (F. Pedroni, dados não publicados).

\section{Discussão}

Fenologia - Copaifera langsdorffii apresenta sazonalidade na perda e produção de folhas, coincidindo com a estação seca, fato que tem sido observado para muitas espécies de Cerrado (Barros \& Caldas 1980, Araujo et al. 1987, Mantovani \& Martins 1988, Oliveira et al. 1991, Miranda 1995, Gouveia \& Felfili 1998, Felfili et al. 1999). Com a troca de folhas gradual, não havendo desfoliamento total e mantendo folhas ativas durante todo o ano, Copaifera langsdorffii pode ser considerada como perenifolia (sensu Sarmiento \& Monasterio 1983). Estas observações coincidem com dados disponíveis para mata de galeria onde predominam espécies perenifólias nas quais o auge da mudança foliar ocorre no período seco (Gouveia \& Felfili 1998). Segundo esses autores, de um modo geral, a perda das folhas na seca resulta em trocas gasosas menos intensas e economia de água. O pico de renovação das folhas ocorreu em seqüência à perda de folhas, no final da estação seca e início da chuvosa, parecendo estar relacionado com a precipitação, pois iniciou-se logo após as primeiras chuvas de setembro. Para Miranda (1995), o período da seca, seguido das primeiras chuvas de setembro, pode ser um estímulo para o início do crescimento vegetativo.

O período de floração foi de cinco meses, iniciando-se também com a estação chuvosa. $\mathrm{O}$ aumento na precipitação média mensal, temperatura média mensal e fotoperíodo correlacionam-se positivamente com o aumento no número de espécies em floração no bioma Cerrado (Mantovani \& Martins 1988, Ivizi \& Araújo 1997).

As espécies arbóreas da vegetação do Cerrado apresentam diversas estratégias de florescimento (Oliveira et al. 1991). Gentry (1974) descreveu diferentes padrões associados ao sistema de polinização, para espécies da família Bignoniaceae. A estratégia cornucópia é a mais difundida e generalizada, sendo muitas vezes associada a espécies com floração sazonal. As plantas com esse padrão produzem uma grande quantidade de flores durante várias semanas e, desta maneira, atraem amplo espectro de polinizadores potenciais. De acordo com o que foi observado para C. langsdorffii neste estudo, este padrão dentre os outros definidos por Gentry (1974) parece ser o que melhor define a estratégia de florescimento da espécie, quanto ao sistema de polinização. No entanto, os eventos sincrônicos de abertura de flores ao longo do período de floração, seguidos de períodos sem flores novas são, até certo ponto, semelhantes ao comportamento de floração episódica observado por Bullock et al. (1983) em Guarea rhophalocarpa (Meliaceae).

Quanto à periodicidade, a floração da população de Copaifera langsdorffii estudada pode ser considerada anual regular (sensu Newstrom et al. 1994), pois apresentou floração na mesma época em 1999/2000 e em 2000/2001 (não acompanhada pelo estudo fenológico, mas note a presença de botões no final do período de observações regulares). Floração similar já havia sido observada em 1998/1999 (P. Oliveira, dados não publicados). No entanto, outras populações da espécie apresentaram floração supra-anual, com ciclos reprodutivos com intervalos de dois a quatro anos (Resende et al.1997).

Em Copaifera langsdorffii, a maturação e dispersão dos frutos na estação seca aumentam a probabilidade de germinação e crescimento das plântulas ainda no período chuvoso seguinte, quando elas são beneficiadas pela umidade e pela abundância temporária de nutrientes, em virtude da decomposição da serrapilheira acumulada na estação seca nestes ambientes (Gouveia \& Felfili 1998, Felfili et al. 1999). Estratégias de frutificação de plantas têm sido relacionadas com mecanismos de dispersão (Mantovani \& Martins 1988). A fenologia de floração está ajustada aos períodos ótimos de dispersão, através de diferentes períodos de desenvolvimento dos frutos (Oliveira 1998). No bioma Cerrado, a maturação dos frutos antes do início das chuvas é favorável, porque as sementes terão melhores condições para se dispersarem e se desenvolverem durante a estação chuvosa (Oliveira 1994).

Biologia floral e visitantes - As plantas da família Leguminosae são polinizadas principalmente por abelhas, mas as Caesalpinioideae apresentam uma grande variedade de agentes polinizadores e incluem flores nectaríferas ou flores de pólen com anteras poricidas (Arroyo 1981, Endress 1994). As Caesalpinioideae nectaríferas possuem flores abertas, usualmente com pólen exposto e com guia de néctar, além de estruturas destinadas a conter e alojar o néctar (Coccucci et al. 1992).

As flores de $C$. langsdorffii possuem atributos que as enquadram na síndrome de melitofilia (Faegri \& van der Pijl 1979), tais como simetria zigomorfa (sépala mais larga e diferenciada), odor suave e adocicado, resistência mecânica, facilidades para pouso, antese diurna e néctar disponível. Estas características, entretanto, não limitam as visitas e nem mesmo a 
polinização por outros insetos, como vespas, moscas e borboletas, podendo atrair uma grande diversidade de visitantes oportunistas à procura de néctar e pólen facilmente acessíveis.

Segundo Arroyo (1981), o sistema de polinização de Copaifera pubiflora Benth., das savanas da Venezuela, é altamente ilustrativo para o padrão de visitantes generalistas/não especialistas, tipicamente encontrados em várias Caesalpinioideae; a espécie é visitada por vários tipos de insetos, incluindo abelhas, vespas e borboletas, sendo as vespas os principais polinizadores.

No presente trabalho, os visitantes mais freqüentes foram abelhas sociais de pequeno porte. A quantidade e diversidade de polinizadores foram semelhantes às observadas na Estação Experimental de Mogi-Guaçu (Crestana \& Kageyama 1989). Tal como no presente estudo, os visitantes mais freqüentes e prováveis polinizadores foram Apis mellifera e Trigona sp.; o comportamento de visitação descrito para Apis mellifera foi semelhante ao observado em Uberlândia; visitas de vespas sociais, dípteros, lepidópteros e coleópteros também foram observadas e eles podem constituir polinizadores secundários.

Sistema reprodutivo e frutificação - Árvores de florestas tropicais, devido ao grande porte, diversidade na morfologia das flores e nos sistemas reprodutivos, apresentam dificuldades para realização das polinizações manuais (Bawa et al. 1990). Isso ocorre com as plantas de Copaifera langsdorffii, que além de serem bem altas, possuem flores pequenas (embora em grande quantidade) e pólen e estigmas também pequenos. Flores diminutas e outras características tais como, floração sincrônica e de curta duração, flores delicadas e fáceis de serem danificadas são comuns a várias espécies de dossel e demandam grande esforço e habilidade para a realização de cruzamentos com sucesso (Bawa et al. 1990).

Outro problema que ocorre nestas espécies e que dificulta o trabalho é a grande perda de flores pós-antese. Segundo Bawa et al. (1990), as razões para essa perda ainda não são muito bem explicadas, mas incluem aborto das flores não polinizadas ou seleção das flores autopolinizadas e de polinização cruzada. Outros fatores que podem estar envolvidos nessa baixa produção de frutos são a limitação de recursos para frutificação, a deficiência na polinização, fatores ambientais, problemas genéticos e predação (Stephenson 1981, Arista et al. 1999).

Os resultados das polinizações manuais e o índice de incompatibilidade (ISI) sugerem que Copaifera langsdorffii é fortemente auto-estéril. Resultado similar foi encontrado para algumas Caesalpinioideae, como Copaifera pubiflora e espécies do gênero Cassia e Bauhinia (Arroyo 1981), Hymenaea courbaril L. (Bawa 1974), Hymenaea stigonocarpa Mart. ex Hayne (Gibbs et al. 1999), e em algumas espécies de Caesalpinia (Lewis \& Gibbs 1999).

Para Copaifera langsdorffii, foram encontrados tubos polínicos em todos os tratamentos observados. Mesmo as diferenças significativas entre o número de pistilos autopolinizados e de polinização cruzada com tubos polínicos não implica na impossibilidade da autopolinização, especialmente em flores como as de C. langsdorffii onde os eventos de autopolinização e geitonogamia parecem responder por $90 \%$ ou mais das polinizações naturais (Arroyo 1979). Qualquer mecanismo de incompatibilidade clássico (Gibbs 1990), envolvendo desenvolvimento diferencial de tubos polínicos teria que ser muito mais forte e evidente que o observado para que pudesse ter efeito sobre o sistema reprodutivo. Diante disso parece não haver um sistema de auto-incompatibilidade clássico que impeça a germinação dos grãos de pólen, crescimento do tubo polínico e até mesmo penetração dos óvulos.

$\mathrm{O}$ que poderia estar ocorrendo seria a presença do sistema de auto-incompatibilidade tardia, que impede o desenvolvimento e maturação dos frutos oriundos de autopolinização. Estudos recentes têm revelado, com freqüência, a ocorrência do sistema de auto-incompatibilidade tardia (LSI), onde não há diferença no desenvolvimento do tubo polínico entre autopolinização e polinização cruzada. (Seavey \& Bawa 1986). Segundo Gibbs et al. (1999), estudos sobre os mecanismos de incompatibilidade em plantas tropicais têm demonstrado um crescente número de espécies apresentando sistema de incompatibilidade tardia em relação àquelas com sistemas convencionais de auto-incompatibilidade.

Entretanto, em C. langsdorffii foi observado que a grande perda dos frutos autopolinizados vai ocorrendo paulatinamente durante o primeiro e segundo meses após o início do desenvolvimento. Muitos trabalhos têm detectado este fenômeno em espécies tropicais, e.g. Vellozia squamata Pohl (Oliveira et al. 1991), Dalbergia miscolobiun Benth (Gibbs \& Sassaki 1998), Gomidesia spp. (Nic-Lughadha 1998), e Casearia grandiflora Camb. (Machado \& Oliveira 2000). O desenvolvimento irregular dos frutos de autopolinização em muitas destas espécies, sugere que a auto-esterilidade pode estar associada à depressão endogâmica, onde alelos recessivos causariam falhas no desenvolvimento e morte 
de embriões autopolinizados, e não a mecanismos de incompatibilidade bem definidos (Nic-Lughadha 1998, Gibbs et al. 1999).

Além do alto grau de auto-esterilidade em Copaifera langsdorffii, notou-se uma baixa porcentagem de frutos desenvolvidos em condições naturais. O reduzido número de frutos tem sido encontrado em várias leguminosas, e as causas podem ser bastante variadas entre as espécies. Arroyo (1979) sugere que a baixa produção de frutos em Copaifera pubiflora estaria relacionada com a alta taxa de polinização geitonogâmica, realizada por abelhas em árvores intensamente floridas, podendo ter ocorrido o mesmo em Copaifera langsdorffii. Os dados do presente estudo confirmam esta idéia na medida em que a produção de frutos por polinização cruzada manual é três vezes maior que aquela derivada de polinização aberta natural. Porém, as observações de predação de sementes no presente estudo e em outros trabalhos com a espécie (Pedroni 1995), sugerem que a predação tem papel importante no número final de frutos maduros.

Agradecimentos - À CAPES e ao CNPq pelas bolsas de mestrado para a primeira autora. Ao Departamento de Ecologia da UnB, pelo apoio financeiro durante a realização do trabalho. Ao Instituto de Biologia da Universidade Federal de Uberlândia, pelo apoio logístico para o trabalho de campo e pelas facilidades de laboratório. Ao Sr. Aldorando Dias Souza, proprietário da Fazenda Capim Branco, pela permissão para trabalharmos em sua propriedade. $\mathrm{O}$ trabalho foi feito no âmbito do projeto CNPq 520872/96-7.

\section{Referências bibliográficas}

ALMEIDA, S.P., PROENÇA, C.E.B., SANO, S.M. \& RIBEIRO, J.F. 1998. Cerrado - Espécies vegetais úteis. CPAC-Embrapa, Planaltina.

ARAÚJO, G.M., FRANCISCON, C.H. \& NUNES, J.G. 1987. Fenologia de nove espécies arbóreas de um cerrado no município de Uberlândia - MG. Revista do Centro de Ciências Biomédicas da Universidade Federal de Uberlândia 3:3-17.

ARISTA, M., ORTIZ, P.L. \& TALAVERA, S. 1999. Apical pattern of fruit production in the racemes of Ceratonia siliqua (Leguminosae: Caesalpiniodeae): role of pollinators. American Journal of Botany 86:1708-1716.

ARROYO, M.T.K. 1979. Comments on breeding systems in Neotropical forests. In Tropical botany (K. Larsen \& L.B. Hohlm-Nielsen, eds.). Academic Press, London, p.371-380.

ARROYO, M.T.K. 1981. Breeding systems and pollination biology in Leguminosae. In Advances in legume systematics (R.M. Polhill \& P.H. Raven, eds.). Royal Botanic Gardens, Kew, p.723-769.
BARROS, M.A.G. \& CALDAS, L.S. 1980. Acompanhamento de eventos fenológicos apresentados por cinco gêneros nativos do cerrado (Brasília-DF). Brasil Florestal 10:713.

BAWA, K.S. 1974. Breeding systems of tree species of a lowland tropical community. Evolution 28:85-92.

BAWA, K.S., ASHTON, P.S. \& SALLEH, M.N. 1990. Reproductive ecology of tropical forest plants: management issues. In Reproductive ecology of tropical forest plants (K.S. Bawa \& M. Hadley, eds.). Unesco, Paris, p.3-13.

BULLOCK, S.H. 1985. Breeding systems in the flora of a tropical deciduous forest. Biotropica 17:287-301.

BULLOCK, S.H., BEACH, J.H. \& BAWA, K.S. 1983. Episodic flowering and sexual dimorphism in Guarea rhopalocarpa in Costa Rican rain forest. Ecology 64:851-861.

COCCUCCI, A.A., GALETTO, L. \& SERSIC, A. 1992. El sindrome floral de Caesalpinia galliessii (FabaceaeCaesalpinioideae). Darwiniana 31:111-135.

CRESTANA, C.S.M. \& KAGEYAMA, P.Y. 1989. Biologia reprodutiva de Copaifera langsdorffii Desf. (Leguminosae-Caesalpinioideae), o "óleo-de-copaiba". Revista do Instituto Florestal 1:201-214.

ENDRESS, P.K. 1994. Diversity and evolutionary biology of tropical flowers. Cambridge University Press, Cambridge.

FAEGRI, K. \& VAN DER PIJL, L. 1979. The principles of pollination ecology. Pergamon Press, Oxford.

FELFILI, J.M., SILVA-JÚNIOR, M.C.S., DIAS, B.J. \& REZENDE, A.V. 1999. Estudo fenológico de Stryphnodendron adstringens (Mart.) Coville no cerrado sensu strictu da Fazenda Água Limpa no Distrito Federal, Brasil. Revista Brasileira de Botânica 22:83-90.

GENTRY, A.H. 1974. Flowering phenology and diversity in tropical Bignoniaceae. Biotropica 6:64-68.

GIBBS, P.E. 1990. Self-incompatibility in flowering plants: a neotropical perspective. Revista Brasileira de Botânica 13:125-136.

GIBBS, P.E., OLIVEIRA, P.E. \& BIANCHI, M.B. 1999. Postzygotic control of selfing in Hymenaea stigonocarpa (Leguminosae- Caesalpinioideae), a bat-pollinated tree of the Brazilian cerrados. International Journal of Plant Sciences 160:72-78.

GIBBS, P.E. \& SASSAKI, R. 1998. Reproductive biology of Dalbergia miscolobium Benth. (LeguminosaePapilionoideae) in SE Brazil: the effect of pistilate sorting on fruit-set. Annals of Botany 81:735-740.

GOUVEIA, G.P. \& FELFILI, J.M. 1998. Fenologia de comunidades de cerrado e de mata de galeria no Brasil Central. Revista Árvore 22:443-450.

INOUYE, D.W., FAVRE, N.D., LANUN, J.A., LEVINE, D.M., MEYERS, J.B., ROBERTS, M.S., TSAO, F.C. \& WANG, Y.Y. 1980. The effect of non-sugar nectar constituents on estimates of nectar energy content. Ecology 61:992-995. 
IVIZI, L. \& ARAÚJO, G.M. 1997. Fenologia de 14 espécies arbóreas de uma floresta estacional decídua no município de Uberlândia, MG. Arquivos de Biologia e Tecnologia 40:883-892.

KEARNS, C.A. \& INOUYE, D.W. 1993. Techniques for pollination biologists. University Press of Colorado, Niwot.

LEITE, A.M.C. \& SALOMÃO, A.N. 1992. Estrutura populacional de copaiba (Copaifera langsdorffii Desf.) em mata ciliar do Distrito Federal. Acta Botanica Brasilica 6:123-134.

LEWIS, G. \& GIBBS, P.E. 1999. Reproductive biology of Caesalpinia calycina and C. pluviosa (Leguminosae) of the caatinga of north-eastern Brazil. Plant Systematics and Evolution 217:43-53.

MACHADO, A.O. \& OLIVEIRA, P.E.A.M. 2000. Biologia floral e reprodutiva de Casearia grandiflora Camb. (Flacourtiaceae). Revista Brasileira de Botânica 23:283-290.

MACHADO, J.W.B. 1990. Relação origem/solo e tolerância à saturação hídrica de Copaifera langsdorffii Desf. Tese de doutorado, Universidade Estadual de Campinas, Campinas.

MANTOVANI, W. \& MARTINS, F.R. 1988. Variações fenológicas das espécies do cerrado da Reserva Biológica de Moji Guaçu, Estado de São Paulo. Revista Brasileira de Botânica 11:101-112.

MARTIN, F.N. 1959. Staining and observing pollen tubes in the style by means of fluorescence. Stain Technology 34:125-128.

MIRANDA, I.S. 1995. Fenologia do estrato arbóreo de uma comunidade de cerrado em Alter-do-Chão, PA. Revista Brasileira de Botânica 18:235-240.

NEWSTROM, L.E., FRANKIE, G.W. \& BAKER, H.G. 1994. A new classification for plant phenology based on flowering patterns in lowland tropical rain forest trees at La Selva, Costa Rica. Biotropica 26:141-159.

NIC-LUGHADHA, E. 1998. Preferential outcrossing in Gomidesia (Myrtaceae) is maintained by a post-zygotic mechanism. In Reproductive biology: in systematics, conservation and economic botany (S. Owens \& P. Rudall, eds.). Royal Botanic Gardens, Kew, p.363-379.

OLIVEIRA, P.E. 1994. Aspectos da reprodução de plantas do cerrado e conservação. Boletim do Herbário Ezechias Paulo Heringer 1:34-45.

OLIVEIRA, P.E. 1998. Fenologia e biologia reprodutiva das espécies do Cerrado. In Cerrado ambiente e flora. (S.M. Sano \& S.P. Almeida, eds.). CPAC-Embrapa, Brasília. p.169-192.

OLIVEIRA, P.E. \& GIBBS, P.E. 2000. Reproductive biology of woody plants in a cerrado community of Central Brazil. Flora 195:311-329.
OLIVEIRA, P.E., GIBBS, P.E. \& BIANCHI, M. 1991. Pollination and breeding biology of Vellozia squamata (LilialesVelloziaceae): a species of the Brazilian cerrados. Botanica Acta 104:392-398.

OLIVEIRA, P.E. \& SILVA, J.C.S. 1993. Reproductive biology of two species of Kielmeyera (Guttiferae) in the cerrados of central Brazil. Journal of Tropical Ecology 9:67-79.

PEDRONI, F. 1995. Ecologia da copaíba. In Ecologia e preservação de uma floresta tropical urbana: Reserva de Santa Genebra. (H.F. Leitão-Filho \& L.P.C. Morellato, eds.). Editora da Unicamp, Campinas, p.70-76.

RATTER, J.A., RIBEIRO, J.F. \& BRIDGEWATER, S. 1997. The Brazilian cerrado vegetation and threats to its biodiversity. Annals of Botany 80:223-230.

RESENDE, J.C., SCHIAVINI, I. \& KLINK, C.A. 1997. Ecological aspects of a Copaifera langsdorffii population in a gallery forest of central Brazil. In Proceedings of the International Symposium on Assessment and Monitoring of Forest in Tropical Dry Regions with Special Reference to Gallery Forest (J.I. Encinas \& C. Kleinn, eds.). Universidade de Brasília, Brasília, p.147-156.

ROSA, R., LIMA, S.C. \& ASSUNÇÃO, W.L. 1991. Abordagem preliminar das condições climáticas de Uberlândia (MG). Sociedade e Natureza 3:91-108.

SARAIVA, L.C., CESAR, O. \& MONTEIRO, R. 1996. Breeding systems of shrubs and trees of a Brazilian savanna. Arquivos de Biologia e Tecnologia 39:751-763.

SARMIENTO, G. \& MONASTERIO, M. 1983. Life forms and phenology. In Ecosystems of the world: tropical savannas (F. Bouliere, ed.). Elsevier Science, Amsterdam, p.79-108.

SCHIAVINI, I. 1997. Environmental characterization and groups of species in gallery forest. In Proceedings of the International Symposium on Assessment and Monitoring of Forest in Tropical Dry Regions with Special Reference to Gallery Forest (J.I. Encinas \& C. Kleinn, eds.). Universidade de Brasília, Brasília, p.107-113.

SEAVEY, S.R. \& BAWA, K.S. 1986. Late-acting selfincompatibility in Angiosperms. Botanical Review 52:195-219.

SOKAL, R.R. \& ROHLF, J.E. 1981. Biometry. Freeman, San Francisco.

STEPHENSON, A.G. 1981. Flower and fruit abortion: proximate causes and ultimate functions. Annual Review of Ecology and Systematics 12:253-279.

ZAPATA, T.R. \& ARROYO, M.T.K. 1978. Plant reproductive ecology of a secondary deciduous tropical forest in Venezuela. Biotropica 10:221-230. 